\title{
The effect of microwax composition on the staining quality of Klowong Batik Wax
}

\author{
Abdul Malik ${ }^{1, *}$, Fety Ilma Rahmillah $^{2}$, Bayu Dwi Atmaja ${ }^{3}$, and Bilal Fatihul Ihsan ${ }^{4}$ \\ ${ }^{1,3,4}$ Department of Chemical Engineering, Islamic University of Indonesia, Jl. Kaliurang Km 14.5, Yogyakarta, Indonesia \\ ${ }^{2}$ Department of Industrial Engineering, Islamic University of Indonesia, Jl. Kaliurang Km 14.5, Yogyakarta, Indonesia
}

\begin{abstract}
Batik is one of the most highly developed Indonesian art forms that had been designated by UNESCO as a Masterpiece of Oral and Intangible Heritage of Humanity. Batik wax is considered as the main material to make Batik, especially for handmade Batik in which the pattern and carve applied directly by the artisans. Melted wax (Malam) is made from a mixture of melted damar mata kucing, gondorukem, beeswax, and paraffin. This study aimed to substitute the beeswax which was difficult to find into microwax made from paraffin which is available in huge amount as well as easily searchable. Microwax varied as many as four samples with the equal variable. The samples were then tested used Spectrophotometer to test the colour difference, colour ageing test, rub test (wet, dry, and endurance soap). The results showed that microwax can be used to substitute the function of beeswax with appropriate composition. It is highly expected that the increasing of melted wax quality can increase the quality of Batik itself as well as the preservation of Indonesian Batik as a cultural heritage.
\end{abstract}

\section{Introduction}

In a piece of batik cloth, there are social, cultural, as well as economic values which promote the honour of Indonesia [1]. In addition, Batik had been appointed as the masterpiece of an oral and intangible heritage of humanity by UNESCO [2]. The batik method dyeing also has been applied to tanned leather [3].

Batik wax is considered as the main material to make Batik, especially for handmade Batik in which the pattern and carve applied directly by the artisans. Batik wax is the material used to cover parts of cloth that are not to be dyed. Batik wax is not only composed of one material, but a mixture of several basic wax materials such as residue of pine-gum distillation (gondorukem), Damar Mata kucing (Shorea javanica), paraffin (white and yellow), microwax, animal fat (Kendal, animal lard), coconut oil, beeswax, and lancing wax. Beeswax is used for its malleability, paraffin is for friability, resins can be added to increase the adhesiveness, while the animal fats can make greater liquidity [8].

All of the ingredients have different prices. Beeswax is the most expensive component which is usually used in the formula to produce the finest quality of batik. Beeswax or lancing wax has been used since the beginning of creating Batik motive process. These animal wax usually called as "malam", therefore it is common to call "malam Batik". At the earlier times, javanese people tend to use beehive for batik, because there is a hexagonal structure made from a kind of wax which composed of ester fatty acid and long-chain alcohol compounds [8].
Experiences made people mix the pure malam or beeswax with plants such as Gondorukem and Damar Mata kucing. Then, animal lard or palm oil can be added to smooth and lower the melting point. In the last process of making batik, the entire wax is removed with hot water added, so that the batik wax off and after water used to remove wax becomes cold, it will be frozen and then it can be taken back. Wax derived from removal called used wax or black wax, because the colour is black. The former wax mixed again in the manufacture of a mixture of new wax. Principally, the work process of malam and dye in making batik use two opposite materials like oil and water. While the oil contains wax, the dye contains water. Certain parts waxed automatically cannot be penetrated by the dye [8].

Research about Batik wax is rarely conducted. Scholar [4] identify the effect of natural resin composition on temperature of wax removing for batik natural dye, while [5] determine the composition of shorea javanica required on klowong batik wax, and [6] research about good quality wax measured by ten testing items that become the standard criterion which has to be done by batik artisans who act as the raters. Study [6] conducted by using a many-facet Rasch model (MFRM) which at the same time measures the quality of the batik wax, the quality of the testing items, and the severity level of the rates. Scholar [7] use another material to make wax, so called soy wax in which the number of material used and the ratio is varied depending on the use and the experiences of the artisan.

According to the literature, no study tries to substitute the beeswax which was difficult to find into microwax

\footnotetext{
*Corresponding author: 815210102@uii.ac.id
} 
made from paraffin which is available in huge amount as well as easily searchable. Therefore, this paper aims to know the potency of microwax as a substitute of beeswax and to know the influence of microwax composition towards a staining quality of Klowong Batik wax.

\section{Method}

The tools used for the experiment are:

a. To make batik patterns: pencil and mori cloth commonly used for batik.

b. To make the sample for experiments: wok (to heat the wax), stove, stirring tool, and mould to relocate the wax samples.

Four samples with different composition of microwax (A-10 gr, B-15 gr, C-20 gr, and D-25 gr) were used. The variations can be used to know its influence on the quality of wax. The experimental steps are making the sample and pattern; the process of making Batik; colouring process; removal wax process; and observation process.

The colouring process for four samples was done by the same treatment with small doses of the same naphthol, soaking the same time and the same drying time. So, from four samples were obtained the results of the same colour and the same relative. After dyeing finished sample of size $5 \times 5$ will be tested by firing spectrophotometer to test how well the wax covers the staining of a pattern. Then, some tests were done to the batik cloth such as dry and wet rub test, colour fastness test, colour ageing tests, and colour different test. The questionnaire was used as a qualitative analysis involving eight respondents and three questions related to the quality of Malam, Batik patterns, and staining results.

\section{Results and Discussion}

This study uses microwax as the material to make Batik wax. Microwax is derived from refined paraffin (wax) which is from petroleum refineries. The properties of microwax resemble beeswax flexible/lithe/ductile and easy to be removed. Its flexibility similar with beeswax (kote), so that it can be used to substitute or reduce the use of beeswax. Microwax properties are melting at 70 degrees Celsius, taking a long time to melt it; easy off in a water bath, hard to penetrate the fabric, and resistant to alkaline solution. Of these properties, microwax was fit to be the main material in this study which is to know the effect of its composition on Batik staining. Here is the results of the tests conducted toward four samples.

\subsection{Dry and Wet Rub Test}

According to the analysis of colour fastness test shown in Figure 1, all the varied experiments showed good index and the different concentration of microwax does not give impact to the colour quality.

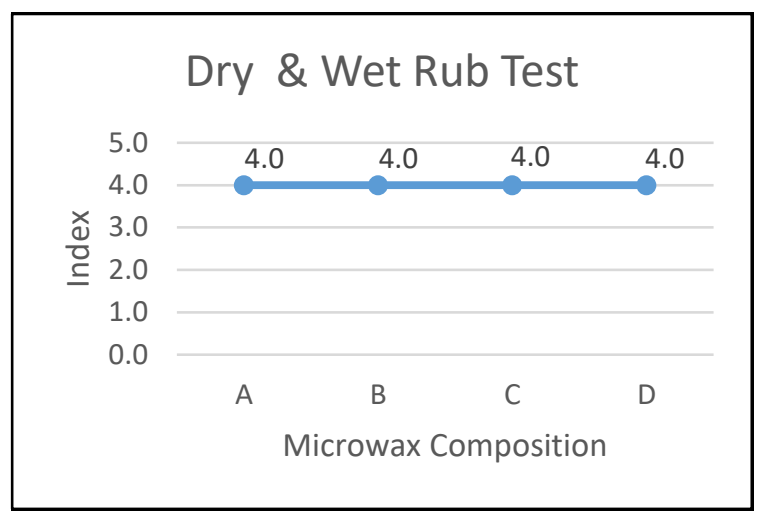

Fig 1. Dry and wet rub test

\subsection{Color Fastness Test}

This test plays an important role because it assesses the fastness of the cloth dyeing as well as it can be used as a decision-making tool in dye selection. Compared to samples A and B, samples $\mathrm{C}$ and $\mathrm{D}$ get a higher value of 4.5 which is just differ 0.5 .

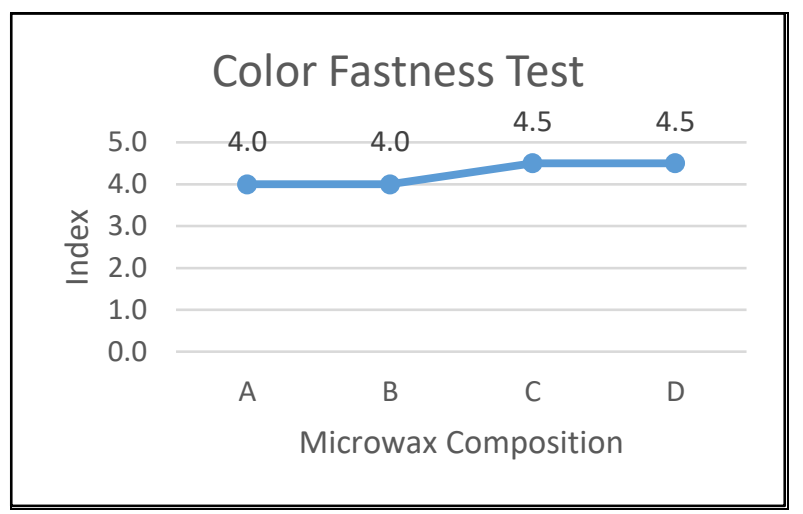

Fig 2. Color fastness test

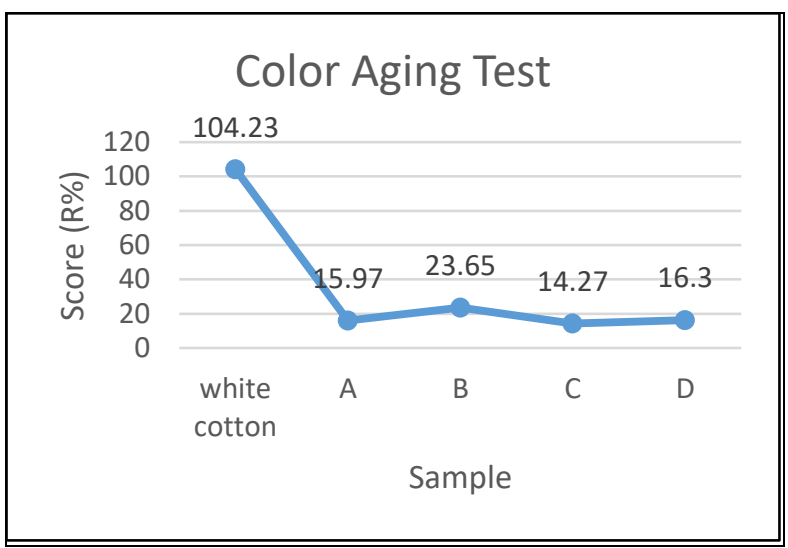

Fig 3. Color aging test

\subsection{Color Aging Test}

The colour ageing test with various microwax variations can be seen in Figure 3. The white cotton value 104.23 is used as a standard to be compared with the samples. The graph indicates that the smaller $\mathrm{R} \%$ value, the darker the fabric fibres, inversely, the lighter the fibres lead to white 
colour in which the standard score of white cotton is 104,23 or called as "blanko". The up and down of the score was due to the differing time of cloth dyeing.

\subsection{Color Different Test (R\%)}

Colour different test with microwax variations can be seen in Table 1. The value of $\mathrm{L}^{*}$ gets down from 96.19 until 68.97 as the smaller the microwax amount. However, the value of * increases from 24.37 into 43.67; and the value of $b^{*}$ goes up from 22.02 to 41.02 ; as well as the value of $\mathrm{dE}^{*} \mathrm{ab}$ which ascends from 33.16 into 67.79 .

Table 1. Color different test (Microwax) (R\%)

\begin{tabular}{|c|c|c|c|c|}
\hline \multirow{2}{*}{$\begin{array}{c}\text { Sample } \\
\text { Code }\end{array}$} & \multicolumn{4}{|c|}{ Color Different Test $\left(\mathrm{L}^{*} \mathrm{a}^{*} \mathrm{~b} * \mathrm{dE} * \mathrm{ab}\right)$} \\
\cline { 2 - 5 } & $\mathrm{L}^{*}$ & $\mathrm{a}^{*}$ & $\mathrm{~b} *$ & $\mathrm{dE} * \mathrm{ab}$ \\
\hline & 100,67 & $-0,01$ & $-0,01$ & 0 \\
\hline A & 96,19 & 24,37 & 22,02 & 33,16 \\
\hline B & 87,68 & 30,06 & 28,15 & 43,19 \\
\hline C & 65,54 & 42,12 & 40,39 & 68,12 \\
\hline D & 68,97 & 43,67 & 41,02 & 67,79 \\
\hline
\end{tabular}

Table 2 shows the data of colour different test without microwax. There is an unstable value of $\mathrm{L}^{*} ; \mathrm{a}^{*} ; \mathrm{b}^{*}$; and $\mathrm{dE}^{*}$ ab which show up and down. Graph 4 shows the relationship between wax from microwax and nonmicrowax.

Table 2. Color different test (NonMicrowax) (R\%)

\begin{tabular}{|c|c|c|c|c|}
\hline \multirow{2}{*}{$\begin{array}{c}\text { Sample } \\
\text { Code }\end{array}$} & \multicolumn{4}{|c|}{ Color Different Test $\left(\mathrm{L}^{*} \mathrm{a} \mathrm{b}^{*} \mathrm{dE}\right.$ *ab) } \\
\cline { 2 - 5 } & $\mathrm{L}^{*}$ & $\mathrm{a}^{*}$ & $\mathrm{~b}^{*}$ & $\mathrm{dE}$ ab \\
\hline & 100,67 & $-0,01$ & $-0,01$ & 0 \\
\hline A & 64,36 & 56,15 & 25,57 & 71,6 \\
\hline B & 60,56 & 58,81 & 27,42 & 76,29 \\
\hline C & 61,89 & 56,58 & 25,13 & 73,06 \\
\hline D & 57,04 & 60,56 & 29,03 & 80,1 \\
\hline
\end{tabular}

The graph illustrates the colour different test result on the various use of microwax composition ranging from zero to hundred. Overall, the more microwax used, the darker the colour and the lower the score of the different colour test. However, sample $\mathrm{C}$ and $\mathrm{D}$ have almost similar results which only differ 3.5 points for five grammes differ composition of microwax.

\subsection{Batik Quality Test from Questionnaire}

Three questions were asked to eight respondents. The questions as follows: how is the quality of Batik wax in colouring the sample cloth; how is the quality of batik pattern visually on the sample cloth; and how is the quality of colouring visually on the sample cloth.

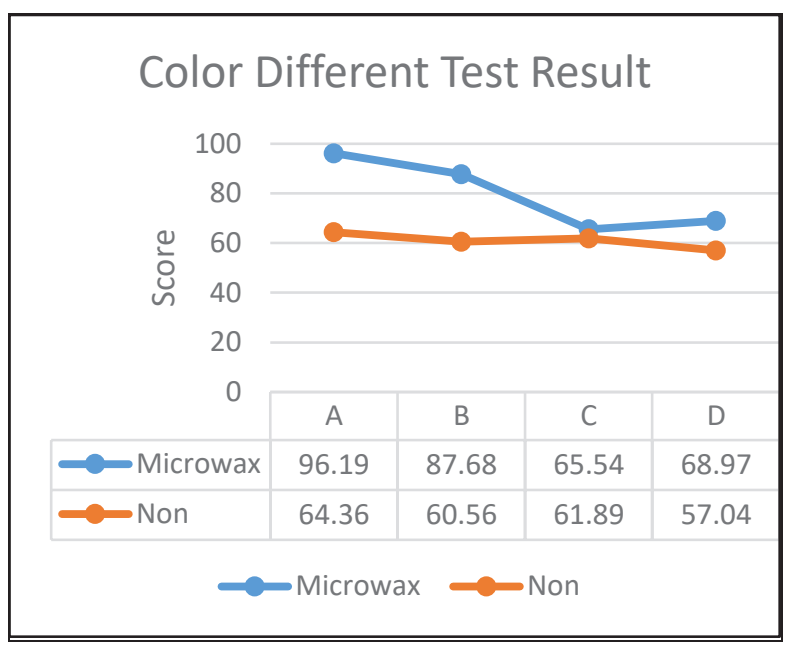

Fig 4. Color different test

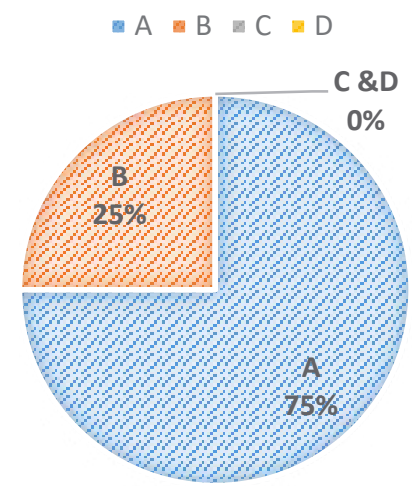

Fig 5. Quality of malam

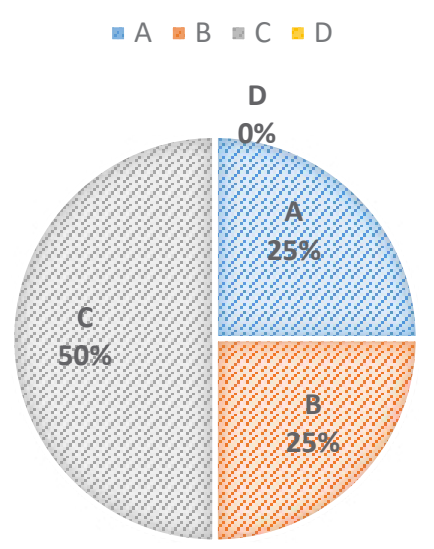

Fig 6. Batik pattern

Figure 5 shows that $75 \%$ respondents prefer sample A as the best malam while the rest of $25 \%$ choose sample B. Figure 5 shows that $50 \%$ respondents vote sample $\mathrm{C}$ as the best batik pattern, followed by sample $\mathrm{B}$ and $\mathrm{C}$ as much as $25 \%$. While the best staining result is sample $\mathrm{C}$ (50\%), sample B (38\%), and sample A (12\%) consecutively. 


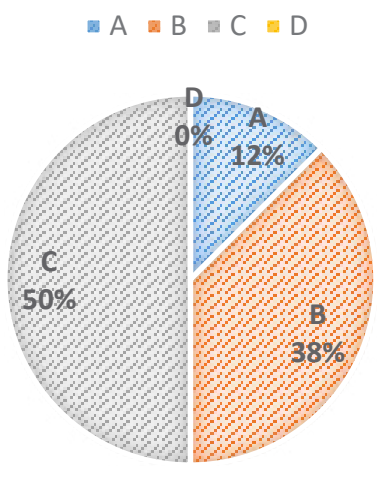

Fig 7. Staining result

In the process of making Batik wax and patterns, the steps were done carefully, especially when the process of Canting made. The researcher created patterns that look good but easily be tested during the process. In the colouring process, red dye naphthol was used so that the colour obtained has a strong colour and clear to make visible differences in colour with a cloth that cover the wax. In the process of removing wax with boiled water and caustic soda, the wax can be separated perfectly without leaving a melted wax around the fabric. The experiment resulted from different Batik wax in terms of colour and texture. The more Microwax composition, the brighter and clear. In terms of the texture, the more Microwax composition makes the cloth softer and easier to dry. While for the closure of the pattern is relatively the same. All samples can cover the pattern as well as resistant to colouring fabric.

\section{Conclusion}

The conclusion can be drawn as follows:

a. The more microwax composition is used, the lower the melting point during the process of melting the raw materials into a wax as well as the clearer and softer of the wax, visually.

c. The more microwax composition does not make the better quality of the wax. The best wax quality is obtained on a sample with the smallest amount of microwax.

d. The composition of microwax must be balanced with other ingredients in order to produce the best quality.

e. Microwax has the same function of beeswax, so that it can reduce the use of beeswax.

\section{References}

1. E. Steelyana, Binus Bussiness Rev. (2012)

2. Unesco, Indonesian Batik - intangible heritage Culture Sector - UNESCO (2009)

3. W. Pancapalaga, P. Bintoro, Y. B. Pramono, S. Triatmojo, Int. J. Appl. Sci. Tech. 4 (2), 236-242 (2014)

4. V. Atika, A. Haerudin, Din. Kerajinan dan Batik 30(1), 23-30 (2013)

5. A. Malik, Nadia, Khairunnisa, Teknoin 22(4), 252 260 (2016)

6. K. Kudiya, B. Sumintono, S. Sabana, and A. Sachari, Pacific Rim Objective Measurement Society symposium (2016)

7. D.B. Bowen, Surface Design J. 32(1), 22-25 (2007)

8. Susanto, S. Indonesian Batik and Handicraft Research Institute (1980) 